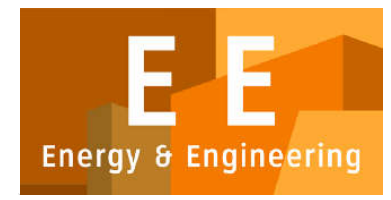

PAPER - OPEN ACCESS

\title{
Perbaikan Sistem Kerja Melalui Analisis Ergonomi
}

\author{
Author $\quad:$ Meri Andrian dan Muhammad Thaib Hasasn \\ DOI \\ : 10.32734/ee.v2i3.743 \\ Electronic ISSN : :2654-704X \\ Print ISSN : $2654-7031$
}

Volume 2 Issue 3 - 2019 TALENTA Conference Series: Energy \& Engineering (EE)

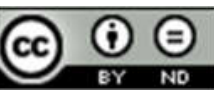

This work is licensed under a Creative Commons Attribution-NoDerivatives 4.0 International License.

Published under licence by TALENTA Publisher, Universitas Sumatera Utara

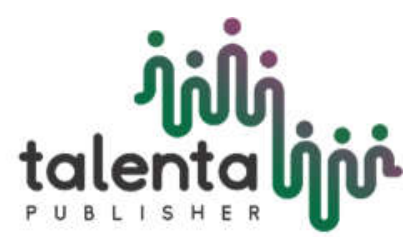




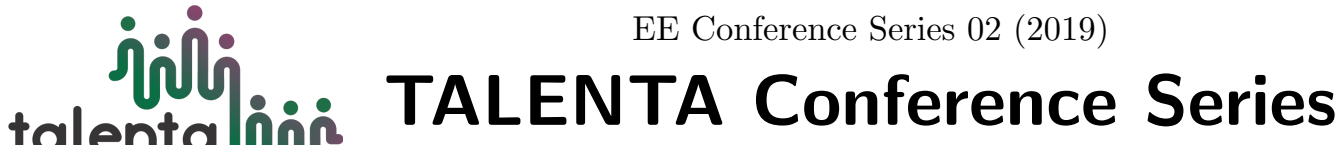

Available online at https://talentaconfseries.usu.ac.id

\section{Perbaikan Sistem Kerja Melalui Analisis Ergonomi}

\author{
Meri Andrian ${ }^{1}$, Muhammad Thaib Hasan ${ }^{2}$ \\ ${ }^{1}$ Teknik Industri, Jl. Meurandeh, Langsa and 24416, Indonesia \\ ${ }^{2}$ Teknik Industri, Jl. Meurandeh, Langsa and 24416, Indonesia \\ meri_tind@unsam.ac.id, mthaeb@yahoo.co.id
}

\begin{abstract}
Abstrak
Pekerja kelelahan dan keluhan akibat pengangkatan pompa yang manual. Penelitian bertujuan menganalisis keluhan musculoskeletal dan memberikan solusi rancangan yang ergonomis. Metode yang dipergunakan adalah Standard Nordic Questionnaire (SNQ), metode Rapid Upper Limb Assesment (REBA), metode maximumum permissible limit (MPL) dan Antropometri. Hasil dan pembahasan adalah pada Standard Nordic Questionnaire (SNQ), keluhan pekerja didapatkan Operator 1 memiliki jumlah keluhan 51 keluhan, operator 2 memiliki jumlah keluhan 42 keluhan, operator 3 memiliki jumlah keluhan 43 keluhan, operator 4 memiliki jumlah keluhan 39 keluhan dan operator 5 dengan jumlah keluhan 43 keluhan. Pada REBA, lima operator, didapatkan pada level resiko 4 dengan tindakan sekarang juga. Antropometri yang dipergunakan adalah dimensi tinggi siku berdiri dan lebar telapak tangan (metacarpal) dan persentil yang dipergunakan adalah persentil 50. Kesimpulannya adalah keluhan musculoskeletal untuk metode SNQ, terdapat seluruh pekerja mempunyai level resiko tinggi yakni diperlukan tindakan segera, kecuali satu pekerja yang mempunyai level resiko sedang, yakni pekerja nomor empat. Pada metode REBA, keluhan musculoskeletal setiap pekerja pada level resiko sangat tinggi dengan tindakan sekarang juga. Rancangan yang ergonomis berupa alat crane, dimana ukuran alat crane tersebut disesuaikan dengan dimensi tubuh manusia.
\end{abstract}

Kata kunci: Antropometri, Rapid Upper Limb Assesment, Postur Kerja, Standard Nordic Questionnaire

\begin{abstract}
Workers fatigue and complaints due to the manual lifting of pumps. The study aims to analyze musculoskeletal complaints and provide ergonomic design solutions. The method used is the Standard Nordic Questionnaire (SNQ), Rapid Upper Limb Assessment (REBA) method, maximum permissible limit (MPL) and Anthropometry methods. The results and discussion are on the Standard Nordic Questionnaire (SNQ), worker complaints obtained by Operator 1 has a number of complaints 51 complaints, operator 2 has a number of complaints 42 complaints, operator 3 has a number of complaints 43 complaints, operator 4 has a number of complaints 39 complaints and operator 5 with number of complaints 43 complaints. In REBA, five operators are obtained at the level of risk 4 with the current action as well. The anthropometry used is the dimension of standing elbow height and width of the palm (metacarpal) and the percentile used is the 50th percentile. The conclusion is musculoskeletal complaints about the SNQ method, there are all workers having a high level of risk that is needed immediate action, except for one worker who has a level of risk medium, namely number four worker. In the REBA method, musculoskeletal complaints about each worker at a very high level of risk with current actions. The ergonomic design is a crane, where the size of the crane is adjusted to the dimensions of the human body.
\end{abstract}

Keywords: Anthropometry, Rapid Upper Limb Assessment, Work Posture, Standard Nordic Questionnaire

(C) 2019 The Authors. Published by TALENTA Publisher Universitas Sumatera Utara

Selection and peer-review under responsibility of The 3nd National Conference on Industrial Engineering (NCIE)

2019

p-ISSN: 2654-7031, e-ISSN: 2654-704X, DOI: 10.32734/ee.v2i3.743 


\section{Pendahuluan}

Sistem kerja terdiri dari manusia, alat, mesin dan lingkungan. Sistem kerja yang baik dari sebelumnya merupakan suatu tujuan yang ingin dicapai oleh industri manufaktur [1]. Menurut [2] Sistem kerja yang paling berperan dalam proses produksi adalah manusia, karena manusia sebagai pelaksana dalam proses produksi. Manusia berperan sentral dalam aktivitasnya yaitu sebagai perencana, perancang, pelaksana, dan pengevaluasian dalam setiap aktivitas (kerja), manusia sebagai sumber tenaga kerja masih dominan dalam menjalankan proses produksi terutama kegiatan yang bersifat berulang [3]. Apalagi manusia bekerja secara manual. Pekerjaan seperti ini dapat menyebabkan cepat mengalami kelelahan dan keluhan musculoskeletal disorders (MSDS). Penyebab utama [4] musculoskeletal disorders (MSDS) adalah postur kerja yang tidak baik dalam melakukan aktivitas ditempat kerja. Aktivitas yang tidak baik ini disebut aktivitas yang tidak ergonomis, aktivitas ini terjadi pada pekerja di perusahaan kecil, bahkan perusahaan besar.

Permasalahan dalam penelitian terdapat pada perusahaan PT.PDAM Tirta Keumuneng Kota Langsa. Pekerja bagian Water Treatment Plant (WTP) pada unit pompa utama berdiri mengangkat pompa utama yang mempunyai berat $50 \mathrm{~kg}$. Pengangkatan pompa utama dilakukan secara manual dan tidak menggunakan alat yang dapat meringankan pekerjaan. Pekerjaan dalam mengangkat pompa dilakukan dengan postur kerja membungkuk dalam waktu yang lama \pm 2 jam. Pekerjaan dalam mengangkat pompa dilakukan pada saat pompa mengalami kerusakan. Kerusakan sering terjadi pada saat musim hujan., maka akan sering melakukan pengangkatan pompa untuk diperbaiki, berbeda pada saat musim kemarau, pekerjaan mengangkat pompa dilakukan satu minggu sekali. Pekerjan mengangkat pompa dengan postur kerja membungkuk dalam jangka waktu lama dan repetitive (berulang) cepat mengalami kelelahan dan mendapatkan beberapa keluhan pada bagian tubuh akibat pengangkatan pompa yang manual. Hal ini diketahui dari hasil wawancara kepada pekerja, mereka mengakui cepat lelah dalam mengangkat pompa dan juga terdapat beberapa keluhan, salah satunya keluhan pada bagian lengan. Pekerjaan dalam mengangkat pompa tersebut diidentifikasi sebagai pekerjaan yang tidak ergonomis, maka tujuan dari penelitian adalah menganalisis keluhan musculoskeletal dan memberikan solusi rancangan yang ergonomis.

\section{Metodologi Penelitian}

\subsection{Obyek dan waktu penelitian}

Obyek penelitian adalah pekerja bagian Water Treatment Plant (WTP) pada unit pompa utama yang berjumlah lima orang. Pengangkatan pompa yang mempunyai berat $\pm 50 \mathrm{~kg}$ dilakukan secara manual, dan repetitif (berulang). Pengambilan data dilakukan pada saat proses pengangkatan pompa pada waktu musim hujan yakni bulan Desember 2019.

\subsection{Prosedur penelitian}

Observasi dan wawancara merupakan kegiatan penelitian yang pertama dilakukan,. Penelitian dilakukan dibatasi hanya masalah manusia, sedangkan sistem kerja yang lain tidak. Data penelitian yang dipergunakan adalah data SNQ, REBA dan dimensi antropometri. Data sekunder yang dipergunakan adalah jurnal dan data perusahaan. Penyebaran kuesioner dilakukan untuk melihat titik keluhan yang dialami oleh pekerja. Ada 28 titik keluhan yang akan diidentifikasi yang terdapat pada kuesioner Standard Nordic Questionnaire (SNQ). Standard Nordic Questionnaire $(S N Q)$ dilakukan untuk mengetahui keluhan subyektifitas pekerja pada saat melakukan pekerjaan [5]. Pengukuran postur kerja dan beban kerja dilakukan, pada penelitian kali ini. Pengukuran postur kerja dilakukan menggunakan metode REBA dan pengukuran beban kerja dilakukan menggunakan metode biomekanika. REBA merupakan pengukuran postur kerja untuk gangguan tubuh secara keseluruhan. [6] REBA dapat digunakan untuk penilaian cepat dari seluruh tubuh sebagai evaluasi beban muskuloskeletal karena postur, pengulangan, dan gaya. REBA juga mengevaluasi pekerjaan atau tugas yang dapat mengekspos pekerja untuk gangguan seluruh tubuh (pergelangan tangan, lengan atas dan bawah, leher, batang, dan kaki). Menurut [7] penilan REBA terdiri atas 2 grup, yaitu: Grup A yang terdiri dari postur tubuh kiri dan kanan dari batang tubuh (trunk), leher (neck), dan kaki (legs), dan Grup B yang terdiri atas postur tubuh kanan dan kiri dari lengan atas (upper arm), lengan bawah (lower arm), dan pergelangan tangan (wrist). Pengukuran beban kerja dilakukan menggunakan biomekanika. Biomekanika adalah suatu bidang yang fokus pada proses mekanika (gaya, momen, kecepatan, percepatan dan tekanan) yang 
terjadi pada tubuh manusia, terkait dengan aktifitas fisik yang dilakukan pekerja [8]. Pengukuran biomekanika dibatasi pada metode maximum permissible limit (MPL). Analisa dilakukan dengan menggunakan dua metode yakni REBA dan MPL. Setelah dianalisa, kemudian dilakukan perancangan ergonomis dengan menggunakan metode antropometri dan persentil. Antropometri merupakan ilmu yang berkaitan dengan penyesuaian dimensi alat terhadapat dimensi manusia, menurut [9] manusia memiliki berbagai ukuran tubuh yang berbeda antara yang satu dengan yang lainnya. Pengukuran antropometri juga menggunakan uji statistik. Uji statistik yang diperlukan adalah uji kecukupan data dan uji keseragaman data. Setelah uji statistk kemudian pengukuran dilakukan menggunakan persentil. Pesentil merupakan suatu pengukuran yang menetapkan ukuran alat yang ergonomis. Menurut [5] persentil dilakukan untuk mencocokkan dimensi manusia pada alat yang akan dirancang. Selanjutnya dapat dibuat kesimpulan dari hasil penelitian.

\section{Hasil dan Pembahasan}

\subsection{Standard Nordic Questionnaire ( $S N Q$ ).}

Pengukuran $S N Q$ dilakukan menggunakan kuesioner, dengan kriteria bobot tidak sakit bernilai 0, agak sakit bernilai 1, sakit bernilai 2 dan sangat sakit bernilai 3. Hasil dari pengukuran $S N Q$ terdapat pada Gambar 1 .

\section{Standard Nordiq Questionnaire}

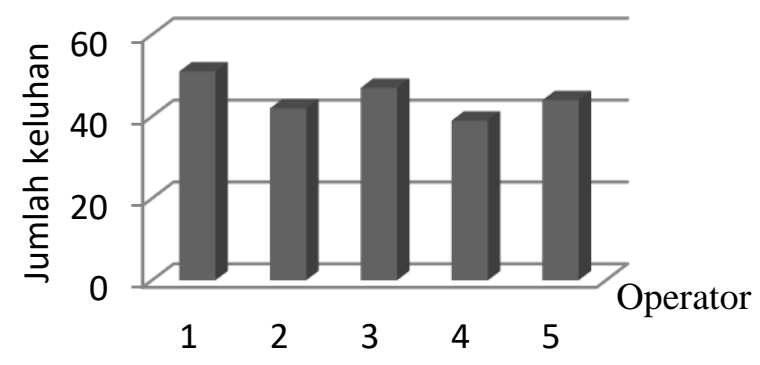

Gambar 1. Jumlah Keluhan Pekerja

Pada Gambar 1 terdapat seluruh pekerja mempunyai level resiko tinggi yakni diperlukan tindakan segera, dkecuali satu pekerja yang mempunyai level resiko sedang, yakni pekerja nomor empat.

\subsection{Rapid Upper Limb Assesment (REBA)}

REBA merupakan pengukuran yang mengidentifikan postur kerja secara keseluruhan, rekapitulasi REBA terdapat pada Tabel 1.

Tabel 1. Rekapitulasi Perhitungan REBA

\begin{tabular}{cccc}
\hline Pekerja & Level tindakan & Level Resiko & Tindakan \\
\hline Pekerja 1 & 4 & Sangat tinggi & Sekarang juga \\
Pekerja 2 & 4 & Sangat tinggi & Sekarang juga \\
Pekerja 3 & 4 & Sangat tinggi & Sekarang juga \\
Pekerja 4 & 4 & Sangat tinggi & Sekarang juga \\
Pekerja 5 & 4 & Sangat tinggi & Sekarang juga \\
\hline
\end{tabular}

Hasil penelitian ditunjukkan pada Tabel 1 bahwa seluruh pekerja mempunyai level resiko sangat tinggi dengan tindakan sekarang juga.

\subsection{Biomekanika}

Beban kerja dianalisa menggunakan biomekanika khususnya maximum permissible limit (MPL), terdapat pada Gambar 2. 


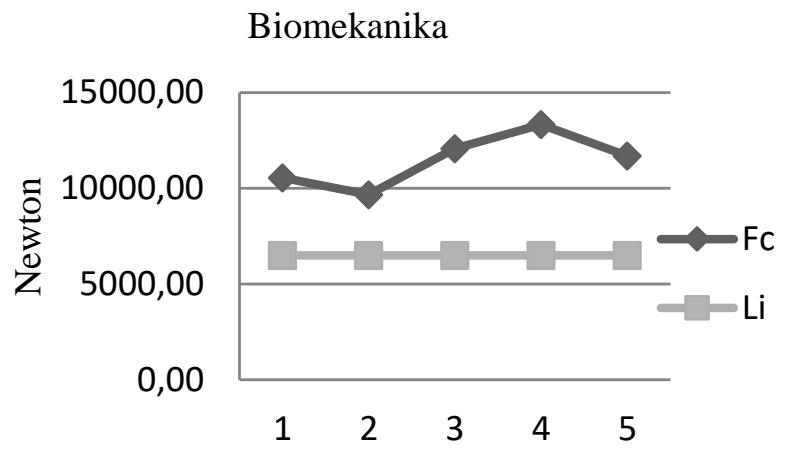

Gambar 2. Perhitungan Maximum Permisible Limit

Gambar 2 memperlihatkan bahwa beban kerja yang diterima oleh 5 operator termasuk dalam kategori berbahaya, karena nilai Fc diatas dari nilai Li.

\subsection{Antropometri}

Antropometri dilakukan untuk mendapatkan perancangan alat yang ergonomis. Dimensi yang dpergunakan adalah dimensi tinggi siku berdiri untuk tinggi alat dan dimensi lebar telapak tangan (metacarpal) untuk lingkaran knop pada alat. Beberapa langkah untuk mendapatkan rancangan ergonomis pada antropometri yakni :uji kesragaman data. Pada uji keseragaman data terdapat pada Gambar 2 dan Gambar 3.

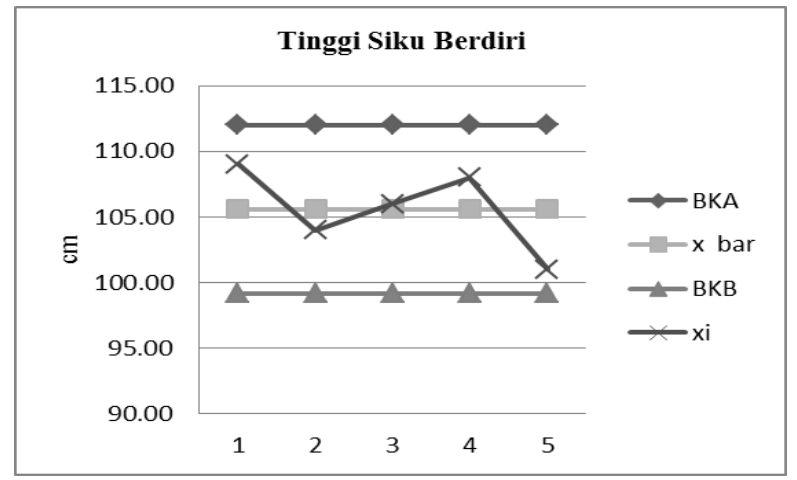

Gambar 2. Dimensi Tinggi Siku Berdiri

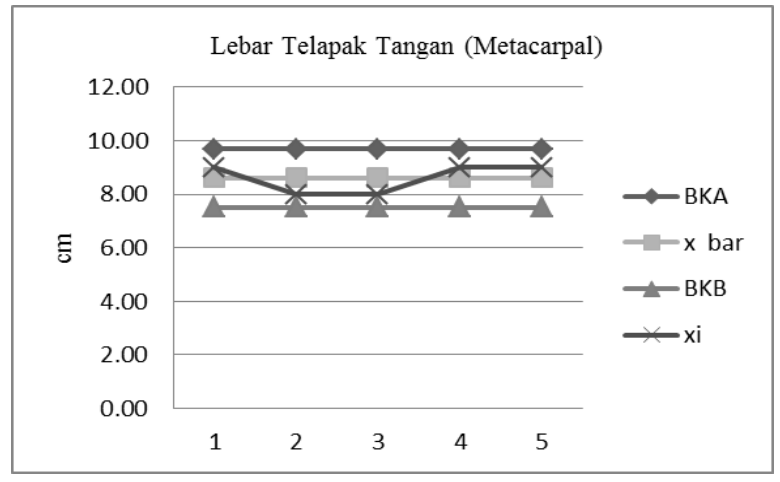

Gambar 3. Lebar Telapak Tangan (Metacarpal)

Gambar 2 dan 3 merupakan rekapitulasi uji keseragaman data dari dimensi yang dipergunakan dalam merancang alat. Terlihat bahwa kedua gambar, data berada didalam batas kontrol, berarti seluruh data seragam. Uji kecukupan data dilakukan untuk kedua dimensi yang dipergunakan, terdapat pada Gambar 4.

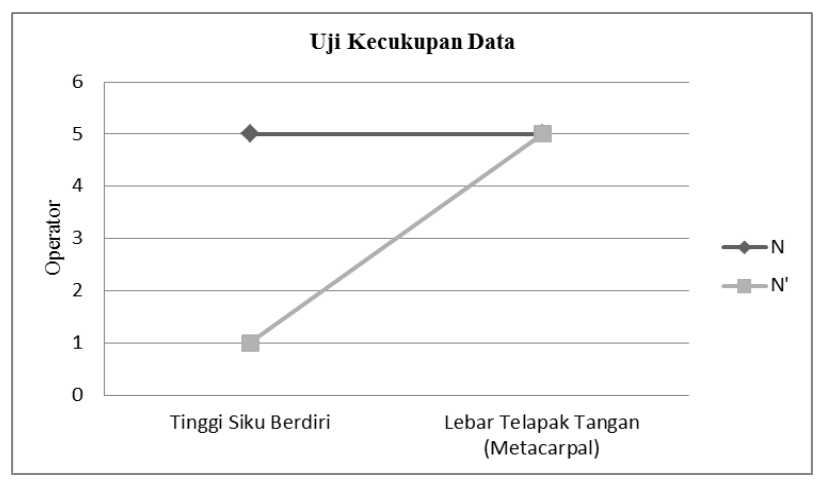

Gambar 4. Uji Kecukupan Data 
Setiap dimensi yang diukur pada uji kecupan data bernilai $N^{\prime} \leq N$, berarti data yang dipergunakan telah cukup untuk melakukan penelitian., terdapat pada Gambar 4.

\subsection{Persentil}

Persentil dipergunakan untuk menetapkan dimensi alat., terdapat pada Tabel 2.

Tabel 2. Persentil

\begin{tabular}{lccc}
\hline \multicolumn{1}{c}{ Dimensi } & P5 & P50 & P95 \\
\hline Tinggi Siku Berdiri & 100,34 & 105,60 & 110,86 \\
Lebar Telapak Tangan (Metacarpal) & 7,70 & 8,60 & 9,50 \\
\hline
\end{tabular}

Tabel 2 menunjukkan bahwa, dimensi tinggi siku berdiri dan dimensi lebar telapak tangan (metacarpal) menggunakan persentil 50 dengan alasan bahwa pekerja memiliki ukuran tinggi dengan rata-rata postur tubuh.

\subsection{Perancangan Alat}

Setelah dianalisis maka dilakukan perancangan alat berupa crane yang terbuat dari plat baja. Alat crane dirancang secara ergonomi agar keluhan dapat dikurangi. Adapun kegunaan dari alat crane adalah :

a. Mengurangi kegiatan membungkuk pada saat pekerja melakukan pekerjaan.

b. Menghindari gerakan jangkauan yang melebihi tinggi batas bahu pada saat berkerja.

c. Pengangkutan mesin pompa lebih mudah.

Alat yang dirancang secara ergonomi terdapat pada Gambar 5.

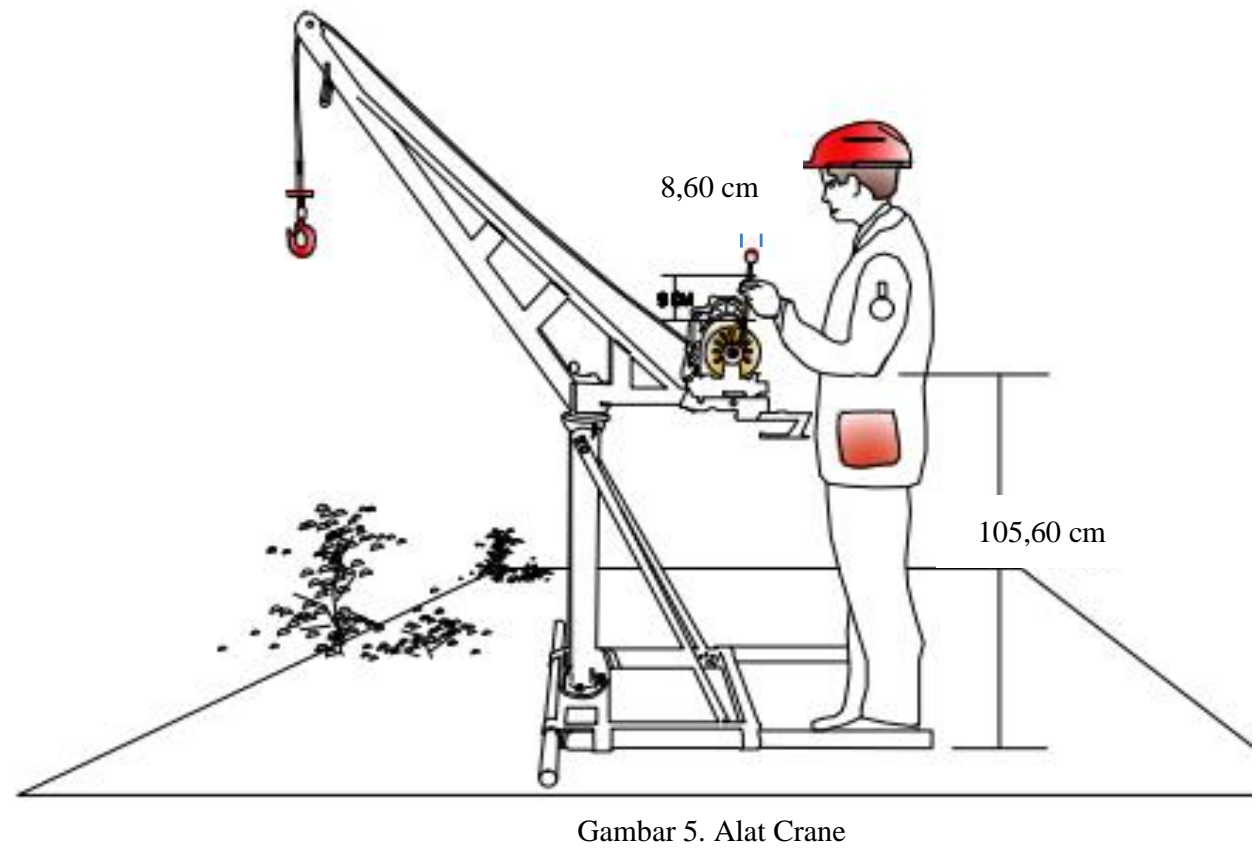

Gambar 5 menunjukkan cara kerja alat :

a. Penggerak menggunakan motor penggerak.

b. Tuas Crane dikontrol menggunakan tombol.

Pekerja mengontrol pengangkatan pompa menggunakan tuas crane, pengangkatan pompa dimulai dengan kawat baja katrol turun kebawah, lalu mengangkat mesin pompa. Kemudian pekerja dapat meletakkan mesin pompa yang sudah diangkat ke lantai, sehingga pekerja tidak perlu menggunakan tenaga ekstra dalam mengangkat mesin pompa. 


\section{Kesimpulan dan Saran}

Kesimpulan dari hasil penelitian adalah :

1. Keluhan musculoskeletal untuk metode SNQ, terdapat seluruh pekerja mempunyai level resiko tinggi yakni diperlukan tindakan segera, kecuali satu pekerja yang mempunyai level resiko sedang, yakni pekerja nomor empat. Pada metode REBA, keluhan musculoskeletal setip pekerja pada level resiko sangat tinggi dengan tindakan sekarang juga.

2. Rancangan yang ergonomis berupa alat crane, dimana ukuran alat crane tersebut disesuaikan dengan dimensi tubuh manusia. Dimensi yang dipergunakan yaitu dimensi tinggi siku berdiri dan lebar telapak tangan.

\section{Acknowledgements}

Ucapan terima kasih penulis ucapkan kepada mahasiswa yang telah membantu dalam mengambil data penelitian.

\section{ReferenSI}

[1] Alfansuri, "Perancangan ulang sistem kerja pada pembuatan kotak surat dengan," vol. 3, pp. 25-30, 2013.

[2] M. Andriani and Anwar, "Perbaikan Sikap Kerja Untuk Mengatasi Beban Kerja," Semin. Nas. IENACO 2018, pp. $27-31,2018$.

[3] M. Andriani and Subhan, "Perancangan peralatan secara ergonomi untuk meminimalkan kelelahan di pabrik kerupuk," Semin. Nas. Sains dan Teknol. 2016 Fak. Tek. Univ. Muhammadiyah Jakarta, no. November, pp. 1-10, 2016.

[4] M. Andriani, "Identifikasi Postur Kerja Secara Ergonomi Untuk Menghindari Musculoskeletal Disorders,” Semin. Nas. Tek. Ind. [SNTI2017] Lhokseumawe-Aceh, pp. 13-14, 2017.

[5] M. Andriani, Dewiyana, and C. I. Erliana, “Analisa Subyektifitas dan Beban Kerja Secara Ergonomi Untuk Meningkatkan Produktivitas," Jurutera, vol. 02, no. 01, pp. 1-4, 2015.

[6] M. Andriani, M. T. Hasan, N. Nazaruddin, and N. Ninafahriana, “Application of Anthropometry to Overcome Musculoskeletal Problems,” J. Phys. Conf. Ser., vol. 1114, no. 1, 2018.

[7] M. Andriani, Dewiyana, and E. Erfani, "Perancangan Ulang Egrek Yang Ergonomis Untuk Meningkatkan Produktivitas Pekerja Pada Saat Memanen Sawit," vol. 4, no. 2, pp. 119-128, 2017.

[8] M. A. Sari, A. Arendra, and S. Akhmad, "Pengembangan Instrumen Esmoca Untuk Pengukuran Sudut 3 Dimensi Alat Gerak Tubuh Bagian Atas Untuk Perhitungan Gaya Dan Momen Biomekanika Kerja,” Tek. Eng. Sains J., vol. 1, no. 2, pp. 77-82, 2017.

[9] D. Arianda, E. R. Sahputra, S. Racman, and Erkadius, "Antropometri sendi pergelangan kaki etnis minangkabau," vol. 38, pp. 108-115, 2015 . 